\title{
Monoclonal Antibodies as Investigative Tools in Onchocerciasis
}

Niklaus Weiss
From the Laboratory of Immunoparasitology, Swiss Tropical Institute, Basel, Switzerland

\begin{abstract}
The development of monoclonal antibodies against parasites can facilitate analysis of host-parasite interactions and can lead to the identification and characterization of antigens that induce protective responses in the immunized host. As diagnostic reagents for human and bovine onchocerciasis, monoclonal antibodies have been used to detect circulating antigens. So far only complex antigens have been used to generate monoclonal antibodies against filarial parasites. The use of such heterogeneous immunogens may result in interference or even in inhibition of the response to the desired parasite antigen(s). Epitopes that are similar or identical to determinants on host molecules or that are components of other infectious agents serve to complicate the generation and selection of monoclonal antibodies against Onchocerca volvulus antigens, and cross-reactivity can be due to monoclonal antibodies reacting with phosphorylcholine, which is present in many preparations of helminth antigens. Because of the host-dependent immunogenicity of filarial agents, reagents should be screened carefully for species specificity by use of a set of different helminth antigens. It is hoped that active collaboration among all investigators engaged in filariasis research will facilitate resolution of such difficulties.
\end{abstract}

The development of monoclonal antibodies to parasites can facilitate analysis of host-parasite interactions and can lead to the identification and characterization of antigens that induce protective responses in the immunized host. Progress of this kind in the field of malaria was recently well documented [1, 2], and in November 1983, the Scientific Working Group on Filariasis conducted a filariasis laboratory workshop in Lille, France, from which it clearly emerged that for filariasis the era of monoclonal antibodies had just begun [3].

I will restrict this background paper to applications of monoclonal antibodies in onchocerciasis. I will include results of published work, data from the Lille meeting, and observations from unpublished work (M. Gualzata, C. Heusser, and N. Weiss). Finally, I will discuss briefly some aspects that complicate the generation and selection of monoclonal antibodies to Onchocerca volvulus and add a list of potential uses of monoclonal antibodies in relation to onchocerciasis.

The work cited in this paper from the author's laboratory received financial support from the Swiss National Science Foundation (grant no. 3.133-0.81).

The author gratefully acknowledges the technical assistance of Regina Rufener, John Bews, Marco Gualzata, and Wyn Davies. Please address requests for reprints to Dr. Niklaus Weiss, Swiss Tropical Institute, CH 4051 Basel, Switzerland.

\section{Generation of Monoclonal Antibodies to Onchocerca Antigens}

At the Lille meeting, 17 monoclonal antibodies from three different laboratories were available. These monoclonal antibodies had been generated with use of either adult $O$. volvulus somatic antigens for immunization (two rat monoclonal antibodies from the Centre d'Immunologie et de Biologie Parasitaire, Lille; 12 mouse monoclonal antibodies from the $\mathrm{Na}$ tional Institute for Medical Research, Mill Hill, London) or Onchocerca gibsoni eggs and microfilariae (three mouse monoclonal antibodies from the Walter and Eliza Hall Institute, Melbourne). The specificity of these monoclonal antibodies was tested by ELISA with use of 37 different filarial and 10 nonfilarial antigens. Sixteen monoclonal antibodies reacted with filarial antigens other than those of $O n$ chocerca. In addition, 12 were reactive with Ascaris lumbricoides adult worm extracts and 10 with Toxocara canis adult worm extracts. Only one monoclonal antibody (2E8Cl, Mill Hill) seemed to be genus-specific reacting only with antigens from O. volvulus, Onchocerca lienalis, and Onchocerca gutturosa female worms. Some of the abovementioned monoclonal antibodies were tested on immunoblots; multiple bands with soluble extracts of $O$. volvulus and Brugia malayi were detected, a finding indicating the presence of common antigenic epi- 
Table 1. Reaction patterns of some monoclonal antibodies obtained after fusion of $\mathrm{P} 3 \times 63(\mathrm{Ag} \mathrm{8.653})$ myeloma cells with spleen cells of a BALB $/ \mathrm{c}$ mouse immunized with Onchocerca volvulus eggs.

\begin{tabular}{lccccc}
\hline & \multicolumn{6}{c}{ Isotype of monoclonal antibody ${ }^{\dagger}$} \\
\cline { 2 - 6 } Antigens* & $\mu$ & $\mu$ & $\gamma_{3}$ & $\mu$ & $\mu$ \\
\hline $\begin{array}{l}\text { Onchocerca volvulus } \\
\text { Dipetalonema viteae }\end{array}$ & ++ & ++ & ++ & ++ & ++ \\
$\quad$ female) & ++ & + & ++ & ++ & ++ \\
D. viteae (male) & + & - & ++ & ++ & + \\
Brugia malayi & + & - & + & ++ & + \\
Ascaris suum & + & - & ++ & ++ & ++ \\
Toxocara canis (larvae) & - & - & - & - & - \\
Schistosoma mansoni & - & - & - & - & - \\
Fasciola hepatica & + & - & - & - & - \\
Echinococcus (hydatid) & + & - & - & - & - \\
Phosphorylcholine-BSA & + & - & - & - & + \\
\hline
\end{tabular}

NOTE. A micro-ELISA system was used to assay antibody. Antigens were coated onto microtiter wells at a protein concentration of $1-5 \mu \mathrm{g} / \mathrm{ml}$. Cell culture supernatant was added to washed plates and incubated for $30 \mathrm{~min}$ at $37^{\circ} \mathrm{C}$. Plates were then washed and incubated for $30 \mathrm{~min}$ at $37^{\circ} \mathrm{C}$ with goat antimouse IgG, IgA, or IgM antiserum labeled with horseradish peroxidase (adsorbed with human serum: Kirkegaard-Perry 14,18-07, Gaithersburg, Md.). Enzyme substrate was added and the color generated was measured at $492 \mathrm{~nm}$ wave length.

* All antigen preparations were PBS extracts of adult worms, except those of $T$. canis (excretory/secretory products of larvae) and of Echinococcus (hydatid fluid).

$\dagger$ Determinations of isotype and antiphosphorylcholine activity were performed by $\mathbf{M}$. Gualzata at the laboratory of Dr. C. Heusser (Ciby-Geigy, Basel). Values indicated as,+++ , and - correspond to $O D$ values of $1.0,0.2-1.0$, and 0.2 , respectively.

topes on different molecules in the crude parasite extracts.

At the Swiss Tropical Institute in Basel, we performed four fusion experiments in 1983 with the aim of generating monoclonal antibodies to infective larvae of $O$. volvulus. In a collaboration with the Onchocerciasis Control Programme (Drs. M. Karam and S. Meredith), we injected four BALB/c mice with 50-80 living larvae harvested from blackflies that had fed on infected human volunteers. In contrast to the response of mice in experiments in which Dipetalonema viteae larvae were used, in these mice the response to infective larvae was very weak, and no monoclonal antibodies with antisurface or antisomatic activity could be isolated.

Early in 1984 we used an immunization scheme similar to that described by Dr. Karen Forsyth [7]; mice were immunized repeatedly with eggs of $O$. vol- vulus (one ip and three iv injections; $10^{4}$ eggs per injection). In a first fusion experiment, 12 monoclonal antibodies were detected with use of an adult O. volvulus antigen in ELISA. Two monoclonal antibodies reacting with a battery of other helminth antigens and to human serum were not recloned. The reaction patterns of five recloned monoclonal antibodies to filarial and other antigens are summarized in table 1. All of these monoclonal antibodies reacted with $O$. volvulus egg membranes and recognized antigens on the egg and the uterus membranes when tested by immunofluorescent assay (IFA) on frozen sections of $D$. viteae female worms. None of the monoclonal antibodies were specific for $O$. volvulus antigen(s). All the monoclonal antibodies reacted with numerous bands on Western blots of a crude antigen extract of adult $O$. volvulus. It has recently been shown that all of the monoclonal antibodies to $B$. malayi except those that recognized stagespecific antigens react with multiple bands on Western blots [4].

\section{Monoclonal Antibodies as Diagnostic Reagents for Onchocerciasis}

So far, application of monoclonal antibodies to onchocerca antigens has been restricted to the detection of circulating antigens associated with human $[5,6]$ and bovine [7] onchocerciasis. Table 2 lists the monoclonal antibodies used either in a radioimmunoprecipitation polyethylene glycol assay (RIPEGA) or in an immunoradiometric assay (IRMA). With both test systems, antigen detection was possible in $70 \%-80 \%$ of microfilaria-positive individuals. Merits and limitations of the two tests were evaluated and discussed at the Lille meeting [3]. Host antibodies seem to interfere in both assays. In two studies $[5,6]$ the prevalence of circulating antigen was highest in children younger than 10 years old. In this age group titers of IgG antibody to $O$. volvulus are significantly lower than in other age groups. False-positive results due to autoantibodies have been observed in the RIPEGA [8], and rheumatoid factors have been found in patients with onchocerciasis [9]. Preliminary experiments conducted at the Lille meeting suggest that it might be possible to eliminate false-positive results by treating sera with acid prior to testing [3]. Acid pretreatment of sera is possible because all three monoclonal antibodies 
Table 2. Monoclonal antibodies used for antigen detection in human and bovine onchocerciasis and bancroftian filariasis.

\begin{tabular}{|c|c|c|c|c|}
\hline Monoclonal antibody & Reference & Immunization & Target antigen & Assay \\
\hline IA2.23 (rat) & 5 & $\begin{array}{l}\text { Onchocerca volvulus somatic } \\
\text { antigen/FCA }\end{array}$ & $\begin{array}{l}\text { "Microfilaria egg cuticle" (TCA } \\
\text { soluble) }\end{array}$ & RIPEGA \\
\hline GIB $13($ BALB/c) & 6 & Onchocerca gibsoni eggs & Egg membrane (TCA soluble, heat & IRMA \\
\hline GIB $86 / 85(B A L B / c)$ & 7 & & and pronase resistant) & \\
\hline
\end{tabular}

NOTE. All four monoclonal antibodies had similar reaction patterns when tested against different helminth antigens in ELISA (Lille workshop). Cross-reactivity was observed with antigens from Onchocerca gutturosa, Onchocerca lienalis, Brugia malayi, Brugia pahangi, Litomosoides carinii, Dipetalonema viteae, and Ascaris lumbricoides. In addition, GIB 13 reacted with hydatid fluid. Abbreviations: FCA = Freund's complete adjuvant; TCA = trichloroacetic acid; RIPEGA $=$ radioimmunoprecipitation polyethylene glycol assay; and IRMA = immunoradiometric assay.

recognize trichloroacetic acid-soluble circulating antigens.

\section{Complications of Generating and Selecting Monoclonal Antibodies to $O$. volvulus Antigens}

So far, only very complex antigens, such as various extracts or intact organisms at different life-cycle stages, have been used to generate monoclonal antibodies to filarial parasites. With such heterogeneous immunogens, the immune response to certain dominant epitopes can interfere or even inhibit the response to the desired parasite antigen(s). In addition, complex antigens may contain epitopes that are similar or identical to determinants on host molecules or that are components of other infectious agents. As an example, molecules bearing phosphorylcholine $(\mathrm{PC})$ were found in bacteria, fungi, and dermatophytes as well as in several helminth parasite species (nematodes, trematodes, and cestodes).

Several investigators have found elevated levels of antibody to PC in mouse sera after injection of the animals with nematode larvae. PC-bearing molecules were demonstrated in extracts of adult worms, larvae, and eggs of Toxocara canis but not in excretorysecretory products of larvae [10]. The immunization of mice with $O$. volvulus eggs has generated monoclonal antibodies with anti-PC reactivity (table 1). It is therefore not surprising that monoclonal antibodies with such reactivity are not $O$. volvulus specific and that they demonstrate cross-reactivity with antigens derived from other filariae or from nonfilarial helminths. Anti-PC monoclonal antibody (kindly supplied by Dr. C. Heusser, Ciba-Geigy, Basel) react with egg and uterus membranes in IFA as well as with many bands of a crude extract of adult $O$. volvulus on immunoblots. Moreover, it has been shown that PC conjugated to a carrier can inhibit the immune response to a hapten attached to the same molecule [11]. These authors suggested that PC-bearing parasite molecules could induce a state of selective tolerance to parasite antigens. We can conclude, therefore, that choosing an "appropriate" antigen is extremely difficult and that generated monoclonal antibodies must be carefully screened for epitope recognition.

Host-dependent immunogenicity of filarial antigens is another aspect to be considered. For example, the immune response to surface antigens is clearly host-dependent; mice but not hamsters recognize the surface of $D$. viteae larvae [12]. Serum antibodies to a major surface component $(20,000$ daltons) of adult $O$. volvulus have been demonstrated in humans with onchocerciasis [13], but several attempts to generate monoclonal antibodies in mice with use of this purified surface antigen for immunization have failed (Dr. R. M. E. Parkhouse, personal communication). It might be interesting to produce human monoclonal antibodies to $O$. volvulus antigens with use of peripheral blood lymphocytes from infected patients; monoclonal antibodies may be produced that are directed against major serologic antigens recognized by the natural host. However, a parasite component that is highly immunogenic in the mouse may be weakly immunogenic in the natural host. Monoclonal antibodies to such antigens eventually could be used for detection of antigen in the serum or urine of infected individuals.

The selection of monoclonal antibodies, especially after immunization with complex antigens, is of crucial importance and must be matched with specific requirements. For diagnostic applications, monoclonal antibodies should recognize $O$. volvulus-specific epitopes of low (in antigen-detection assays) or 
Table 3. Potential uses of monoclonal antibodies in onchocerciasis.

\begin{tabular}{|c|c|}
\hline & Goals \\
\hline \multicolumn{2}{|l|}{ Antigen detection } \\
\hline \multirow[t]{4}{*}{$\begin{array}{l}\text { Detection of infected } \\
\text { individuals }\end{array}$} & $\begin{array}{l}\text { Replacement for parasitologic } \\
\text { methods }\end{array}$ \\
\hline & $\begin{array}{l}\text { Identification of recent } \\
\text { infections }\end{array}$ \\
\hline & Estimation of worm load \\
\hline & Identification of patients at risk \\
\hline $\begin{array}{l}\text { Monitoring of chemo- } \\
\text { therapy }\end{array}$ & Evaluation of efficacy of drugs \\
\hline \multirow[t]{4}{*}{$\begin{array}{l}\text { Identification of para- } \\
\text { site antigens }\end{array}$} & $\begin{array}{l}\text { Taxonomic identification of } \\
\text { infective larvae }\end{array}$ \\
\hline & Analysis of "strain" differences \\
\hline & $\begin{array}{l}\text { Control of antigen fractions } \\
\text { during antigen purification }\end{array}$ \\
\hline & Detection of gene products \\
\hline $\begin{array}{l}\text { Detection of Onchocerca } \\
\text { volvulus-specific host } \\
\text { antibodies }\end{array}$ & $*$ \\
\hline \multirow[t]{2}{*}{ Purification of antigens } & Isolation of pure antigens \\
\hline & $\begin{array}{l}\text { Depletion of unwanted antigens } \\
\text { from crude parasite extracts }\end{array}$ \\
\hline $\begin{array}{l}\text { Analysis of antibody- } \\
\text { mediated effector } \\
\text { mechanisms }\end{array}$ & $\begin{array}{l}\text { Identification of host-protec- } \\
\text { tive antigens (for active } \\
\text { immunization) }\end{array}$ \\
\hline $\begin{array}{l}\text { Targeting of antiparasite } \\
\text { drugs }\end{array}$ & $\begin{array}{l}\text { Elimination of parasite } \\
\text { population }\end{array}$ \\
\hline
\end{tabular}

* See goals for "detection of infected individuals."

high (in competitive immunoassays) immunogenicity. Since no specific antigen probe is available, the screening of monoclonal antibodies must include a battery of carefully selected helminth antigens. Monoclonal antibodies should be screened not only against parasite extracts but also against metabolic and surface antigens, which are potential targets for protective immune responses. When analyzing monoclonal antibodies for antiparasite activity, one should bear in mind that antibody-dependent cellmediated cytotoxicity reactions may be restricted to certain isotypes; i.e., the clearance of $D$. viteae microfilariae in mice is mediated by IgM but not by IgG antibodies [14].

\section{Potential Uses of Monoclonal Antibodies in Onchocerciasis}

There is a wide range of applications for monoclonal antibodies in immunoparasitologic research and in diagnosis of parasitic diseases [15]. Table 3 summarizes the potential uses of monoclonal antibodies and lists specific goals related to their use in onchocerciasis. This list is likely to be incomplete. Achievement of each goal will require intensive work and substantial funding; it is my opinion that success in overcoming the difficulties involved can best be facilitated by a concentration of efforts in filariasis research. It is our task to stimulate collaboration among investigators actively engaged in filariasis research.

\section{References}

1. Nussenzweig RS. The application of monoclonal antibodies to studies of malaria. In: Houba V, Chan SL, eds. Properties of the monoclonal antibodies produced by hybridoma and their application to the study of diseases. Geneva: UNDP World Bank/WHO, 1982:63-9

2. Cohen S. Monoclonal antibodies in parasitology with particular reference to malaria. In: McMichael AJ, Fabre JW, eds. Monoclonal antibodies in clinical medicine. London: Academic Press, 1982:311-31

3. Report of the meeting of the Scientific Working Group on Filariasis. The application of monoclonal antibodies to immunodiagnosis and studies of antigens in filariasis (laboratory workshop). Document TDR/FIL/MAB-DIAG/

83.3. Geneva: WHO/TDR, 1984

4. Canlas, MM, Piessens WF. Stage-specific and common antigens of Brugia malayi identified with monoclonal antibodies. J Immunol 1984; 132:3138-41

5. Des Moutis I, Ouaissi A, Grazych JM, Yarzabal L, Haque A, Capron A. Onchocerca volvulus: detection of circulating antigen by monoclonal antibodies. Am J Trop Med Hyg 1983;32:533-42

6. Forsyth K. PhD diss, Melbourne: University of Melbourne, 1984

7. Forsyth K, Copeman DB, Mitchell GF. Oncocherca gibsoni: increased levels of circulating egg antigen associated with chemotherapy of bovine onchocerciasis. Exp Parasitol, 1985 (in press)

8. Hamilton RG, Hussain R, Alexander E, Adkinson NF. Limitations of the radioimmunoprecipitation polyethylene glycol assay (RIPEGA) for detection of filarial antigens in serum. J Immunol Methods 1984;68:349-66

9. Kawabata M, Flores GZ, Izvi S, Kobayakawa T. IgM rheumatoid factors in Guatemalan onchocerciasis. Trans R Soc Trop Med Hyg 1984;78:356-8

10. Sugane K, Oshima T. Activation of complement in C-reactive protein positive sera by phosphorylcholine-bearing component isolated from parasite extracts. Parasite Immunol 1983;5:385-95

11. Mitchell GF, Lewers HM. Studies on immune responses to parasite antigens in mice. IV. Inhibition of an anti-DNP antibody response with the antigen, DNP-ficoll containing phosphorylcholine. Int Arch Allergy Appl Immunol 1976;52:235-40

12. Weiss $\mathbf{N}$, Tanner M. Immunogenicity of the surface of filarial larvae (Dipetalonema viteae). Trans R Soc Trop Med Hyg 1981;75:179-81 
13. Philipp M. Identification of an antigen of Onchocerca volvulus of possible diagnostic use. Parasitology 1985;89: 295-309

14. Thompson JP, Crandall RB, Crandall CA, Neilson JT. Clearance of microfilariae of Dipetalonema viteae in $\mathrm{CBA} / \mathrm{N}$ and CBA/H mice. J Parasitol 1979,65:966-9
15. Mitchell GF. Uses of monoclonal antibodies in immunoparasitology. In: Houba V, Chan SL, eds. Properties of the monoclonal antibodies produced by hybridoma and their application to the study of diseases. Geneva:UNDP/ World Bank/WHO, 1982:57-62 